\section{ON THE USE OF MODIFIED OPIUM-SMOKING IN PULMONARY TUBERCULOSIS. ${ }^{1}$}

\section{By JOHN GORDON DILL, M.A., M. D,} ASSISTANT PIINSICIAN to TIIE SUSSEX COUNTI HOSPITAL.

SINCE Koch made the first announcement of his remedy for tuberculosis, several other plans for the treatment of this terribly destructive disease have been brought before the medical profession, some of which have been the work of bondfide observers, who were stimulated by the publication of Koch's researches to make known the results of their own labours in the same field, and others, perhaps, worthless imitations, brought forward by charlatans who hoped to float into publicity upon the wave of popular opinion which was directed to the subject. Let me preface my remarks, however, by saying at once that it is not in any sense as a "cure for consumption" that I wish to bring the question of opium-smoking before the profession, but simply because my experience of it has led me to the conclusion that it is a valuable palliative, and therefore of service, as an aid to other measures, in the treatment of the disease. I was greatly struck a few years ago, in reading an article written about China, to find it stated that in certain districts of that country where tuberculosis was extremely prevalent, the opium-smoking population were almost exempt from the disease, and this induced me to try the effect of a mixture of opium and tobacco npon some of my pulmonary patients, in a tentative way at first, and in small quantities, and, I regret to say, without keeping a careful record, for it was only when $I$ found that the patients almost invariably expressed themselves relieved by it, and secmed better, that I began to note with accuracy the amounts given and any change which took place in the condition of the patient. Ny custom has been to soak the tobacco in Battley's liquor opii sedativus, choosing this preparation because it contains all the component parts of opium in a fluid form, and to use it when it has dried. I have given this mixture in various proportions, and I think that a useful strength is three fluid drachms of the Battley to one ounce of tobacco, but of course it can be made much stronger than this. I usually advise the patient not to smoke just before eating, and I never in any case tell him how the tobacco is medicated. The most marked therapeutic effects of smoking opium in this way are that it eases the cough, and acts as an expectorant, "cuts the phlegm," as the patient of ten expresses it. One poor man assured me that he had not the strength to get up in the morning until he had smoked part of a pipe to relieve his chest. The material which I have collected is not yet sufficiently large to draw any conclusion as to whether opium administered in this form has any specific effect upon the disease, although almost without exception the phthisical patients to whom I have given it bave thought that they derived great benefit from its use; nor has sufficient time elapsed, as I have only employed it for two years, to make sure that the improvement which has taken place in any case is permanent. In this connexion two sources of error in considering the effects of any treatment upon the course of pulmonary tuberculosis have, I think, been quite left out of sight in the numerous statistics which have recently been published. The first is the fact that tuberculosis is an undoubtedly curable disease in certain cases, and it is quite possible to conceive that a coincidence of the cure and of the particular treatment adopted may explain many excellent results. The following case is an illustration of this in my recent experience.

J. D-, aged twenty-seven, a tailor by trade, came to see me on Nov. 25th, 1890. He was extremely emaciated and weak, and so short of breath that he even spoke with difficulty. About Nov. 2nd he had suffered from severe hæmoptysis at intervals for a week, losing, his friends told him, "almost three quarts of blood altogether." Before this he had been wasting very rapidly for six months. He had a terrible cough and profuse expectoration. Physical examination of the chest revealed extensive disease at both apices, evidently breaking down, with a cavity about three inches below the right apex. On Nov, 28th be began opiumsmoking. I will not give details of very full notes of this case ; but at first the patient was extremely ill, and upon

1 A paper read before the Brighton and Sussex Medico.Chirurgical Society on May 7 th, 1891 . several occasions he was too weak to come to see me. However, about the middle of January he bad greatly improved, and his night sweats had stopped. He hail no hamoptysis after I first saw him, although he had the taste of blood in his mouth at times for a week or two, and his very rapid pulse made me fear that it was impending. On the 3rd of February, 1891, his weight was 9 st. $12 \mathrm{lb}$; on the $17 \mathrm{th}, 10 \mathrm{st} .3 \mathrm{lb}$; on the $3 \mathrm{rd}$ of Marcí, 10 st. $5 \mathrm{lb}$; on the $17 \mathrm{th}, 10 \mathrm{st} 10 \mathrm{lb}$; on the 3lst, 10st. 13. lb. ; on the 14th of April, 10 st. $13 \frac{1}{16}$.; on the $28 \mathrm{th}, 11 \mathrm{st}$. $4 \frac{1}{\mathrm{l}} \mathrm{b}$; and on May 5th, 11 st. $1 \frac{1}{2} 1 \mathrm{~b}$. On the 28th of April physical examination revealed great flattening of the upper part of the chest in front on both sides, with dropping of the right shoulder. Very deficient breathing at both apices, but no moist sounds. The cavity distinct below the right apex, with whispering pectoriloquy, but apparently perfectly dry. The patient has put on flesh rapidly, and is now fairly well nourished; in fact, he seems on the road to $a$. cure, whether lasting or not it is of course impossible to say. He asked me if he might go back to work, and evidently considers himself nearly well. He is no longer in a hectic condition, and at present no bacilli can be found in his sputa.

The second possible source of error is that it is quite exceptional for a case of pulmonary tuberculosis to go steadily from bad to worse; but, on the contrary, there are, as a. rule, in the course of the disease, periods of intermission in its progress in which the patient improves to a great extent in his general health, and when for a time the symptoms are relieved or disappear, to come on again, perhaps with increased violence, in a few weeks or months. Now, if during the whole of this time a certain treatment has beem pursued, it is difficult to avoid being deceived by the improvenent until a rude awakening is brought about by renewed activity of the disease.

I bave before me the case of a patient, C. F__, who bas smoked opium almost continuously since July, 1889. He stopped it for a time, when his appetite was failing, as $\mathrm{I}$ feared that this might be an eftect of the treatment. He was in an advanced stage of phthisis, and had the usual train of synıtoms, but now for more than a year there has been no bamoptysis, and although his respiration is very rapid and shallow, and the expansion of his chest very limited in extent, no moist sounds are to be heard, and apparently the disease is at a standstill. His weight on Sept. 23rd, 1890, was 9 st. $11 \mathrm{lb}$, and on May 1st, 189l, 9 st. $10 \mathrm{lb}$. It has remained at about this point during the interval, his highest weight being $10 \mathrm{st}$. $1 \mathrm{lb}$, and the lowest 9 st. $7 \mathrm{lb}$, increasing up to Nov. 4 th, 1890 , and then diminishing gradually until Ápril 17th, 1891, since which time it has again increased.

Another very instructive case in this connexion is that of $\mathrm{H} . \mathrm{P}-$, a clerk aged forty, who had been obliged tc give up work, and who came to see me at the end of July, 1889, with very advanced tuberculosis of both lungs. I gave him opium to smoke, and he improved for about two months very rapidly. He then received a letter for the Brompton Hospital, and, as he was in very distressed circumstances, advised him to go in for the winter. When he left Brompton he insisted upon coming down to Brighton, although he was in the very last stage of the disease, and could scarcely get up to the hospital, as he thought that the only benefit he had received was under my treatment. I gave him ar unlimited supply of medicated tobacco ; but he died within a few weeks, although to the last he smoked nearly all day, and suid that it gave him more relief than anything else. Here, of course, was a patient who happened to come to me during one of the periods of quiescence of the disease, and who therefore not unnaturally attributed the improvement in his condition to the treatment he received.

A similar instance is afforded by a poor fellow who had been obliged to give up his work as an official upon the railway, and was going down hill rapidly, but who improved so much with rest and opium-smoking that, very much against my advice, he has gone off his club and resumod work. I fear that in all probability he will come back to me presently, and possibly in a very much worse state than at first.

Another source of error to be guarded against, although not so misleading as the last mentioned two, as it can be checked by the actual phthisical signs, is the hopeful disposition of most phthisical patients, the enthusiasm with which they adopt any new treatment, and their self-deception as regards its effects-a sanguine mental state which is apt to be very contagious.

And now a word of warning as to the use of such an edged 
tool as opium. We certainly do not inject an unknown poison into the system to work its wicked will independent of our control; but, on the other hand, we may be the means of introducing a moral poison, the terrible nature of which can only be realised by those who have had the painful task of trying to cure a victim of the opium habit, and for this reason $I$ have made it a practice never to allow my patients to know what they are smoking, merely calling it medicated tobacco. ${ }^{2}$ At the same time $I$ cannot help thinking that the dangers of smoking opium are greatly exaggerated, although I suppose that, like so many things, it is liable to abuse. I have smoked it myself, by way of experiment, in various strengths up to the pure drug, and have found it very disagreeable, but beyond that it has produced absolutely no recognisable effect. Certainly I have experienced a slight giddiness similar to that which is cansed if I smoke strong tobacco, but nothing else ; and among my patients in no case have I observed the usual well-known symptoms caused by taking opium internally, nor can I remember it to have distinctly caused even drowsiness. If the stories of Chinamen taking three or four whiffs and lying back in blissful unconsciousness are true, as they undoubtedly are, I should imagine that they must either swallow the smoke and so get the opium internally, or else that they do not use pure opium, but a mixture of opium with other things. That the therapeutic effects of a drug should be different when it is used in different ways, is in noway surprising if we only for a moment consider the analogous case of tobacco. My own experience is borne out by a recent writer upon opium dens in London, who smoked, as he says, "four good pipes" in the Chinese fashion, prepared for him by a Chinaman, with absolutely no effect. He asserts, upon the authority of his Chinese friend, that "the supposed state of awful intoxication is a myth."

Now, regarding the patients' own estimate of the value of opium-smoking, the very obvious suggestion arises that if we give tobacco, in no matter what form, to our outpatients, they will of course say that it does them good; but, strong as this argument appears, it can hardly in fairness be applied to a patient who is very ill with pulmonary tuberculosis, or to one unaccustomed to smoke, nor of course to those in good circumstances; and it is con. tradicted, moreover, by the fact of their sometimes asking to have their own tobacco medicated for them. Further, I shall no doubt be reminded of the traditional maxim that nothing can be learned from ont-patients; but in the case of pulmonary tuberculosis I entirely differ from this theory. On the contrary, I think that a far better estimate can be made of the specific action of any treatment if during its administration the patient is left in his usual circumstances, than if he is put into the different, and perhaps very much healthier and more comfortable, surroundings of a hospital ; and I have very little doubt that a large proportion of the good done by special hospitals is due to the change for the better in the conditions of the patient's life. Many patients suffering from phthisis are obliged to give up work, and so feel the pinch of poverty, become ill-nourished and weak, and the disease makes rapid strides; but when they are transferred to a warm and comfortable hospital, and get the best possible food and treatment, the pace down hill is slowed, and an improvement, either temporary or permanent, takes place.

Unfortunately, we have no specific remedy for tuberculosis; time enough has not yet elapsed since the introduction of the new and much vaunted methods of treatment to allow a certain judgment to be formed of their value, and, even if adverse criticism be rejected, the only possible attitude with regard to them is at best an agnostic one. No doubt in time to come we or our successors will be able to battle confidently with this most fatal disease; but at present we must welcome every means of treatment which will give a measure of ease to our patients, or which appear to offer any help to Nature in the efforts which she undoubtedly makes to conquer the morbid process. It is in this sense, and in this sense only, that I have brought the matter of opium-smoking before the profession. Whether the drug administered in this way has any definite effect upon the disease I cannot of course pretend to say. Possibly

2 A difficulty arose in prescribing, as chemists are not allowed uniler the licensing laws to sell tobacco. A suggestion, however, which seems to meet the case, was made by Messrs. Savory and Moore, and approved by other chemists, that I should flavour the Battley or a watery preparation of opium of the same strength, with a little Tonquin bean, and call it liquor thebaicus compositus, to avoid the name of opium, Then a liquor thelaicus compositus, to avoid the name of opium. how to mix it with his tobacco in the proper proportions. in the course of time an analysis of collected material may point to a conclusion one way or the other; but it is because it has seemed to do good that $I$ have ventured to ask that it be given a trial, nob as a substitute for the treatments which professional skill and experience have been led to adopt, but as a possible aid to it.

Brighton.

\section{A CASE OF CEPHALIC TETANUS.}

BY EDWARD ROBERTS, M.R.C.S.,

ASSISTANT SURGEON TO THE ROYAL EYE HOSPITAL, MANCHESTER.

With Microscopical Examination

By R. T. Williamson, M.D., M.R.C.P.

THE following case of cephalic tetanus occurred at the Royal Eye Hospital, Manchester, in July, 1889:-The patient was admitted under the care of Dr. Glascott, who has kindly allowed me to make use of the case. Dr. Williamson has made a careful microscopic examina. tion of some of the nerves and the base of the brain, and his results and methods of examination are fully recorded at the end of this paper.

Arthur B. H- aged sixty.four, was admitted into the hospital on July 1st, 1889. He was a gardener, and was a healthy, wiry looking man. The following history was obtained, partly from the patient and partly from his friends:- While at work on June 26 th he ran his face against a sharp-pointed piece of stick which he was holding in his hand, and which he had just pulled out of the earth. He thought nothing of the wound, and continued at his work till June 30 th, when, noticing some difficulty in mastication, he consulted a doctor, and was advised to come to this hospital. I saw the patient on the night of admission, he then had well-marked trismus, and I ordered him fifteen-grain doses of chloral hydrate. The next morning I examined him carefully, and took the following notes:-July 2nd: The patient has had a restless night; he refuses to take any more chloral hydrate, as he says it makes him worse. There is a horizontal cut a quarter of an inch long just below the left lower eyelid, the edges of the wound are of a bluish colour, the base is indurated, and there is a slight discharge; the wound is a superficial one. The left eye is completely fixed; the pupil moderately dilated, and does not react to light. Vision is said to be good. In the right eye the movements are normal; the pupil is extremely small ; vision is said to be good. The jaw is tightly closed, and during the paroxysms of contraction the patient grinds his teeth in a horrible manner. He has no difficulty in swallowing, taking milk and beef-tea from a feeder, through a gap between his teeth. He is quite conscious, and can say a few words with difficulty. The facial muscles of the right side are in a state of tonic contraction, while those of the left side are completely paralysed; the face ia consequently drawn to the right side, and the tip of the nose is bent markedly over to this side. The contraction of the muscles of the right side of the face and those of the lower jaw are the only signs of tetanus; the slightest noise, such as opening the door or a footstep, brings on severe paroxysmal attacks. Patient complains of pain, which runs from the left ear down the left side of the lower jaw; there is no hyperasthesia or anæsthesia. The morning temperature is $994^{\circ}$, the pulse 98 and full, and the breathing quiet. Ordered fifteen-minin doses of tincture of opium, and as much fluid nourishment as be can take. Evening temperature $100 \cdot 2^{\circ}$; pulse 98 and full.-3rd : Dr. Ross kindly called and examined the patient, who is worse to-day; he always lies on the left side with his head over the bed, and keeps blowing out saliva, which seems to be secreted in large quantities. He cannot swallow, and on taking a mouthfud of milk it comes spluttering out through his mouth and nose. All the conditions noted yesterday are present to-day, but there are now, in addition, the following. During the paroxysmal attacks there is marked hardening of the muscles of the abdomiaal walls. The third and fourth nerves on the right side are paralysed, as shown by ptosis, and complete inability to move the right eye in any direction but outwards; the movement ever in this direction is imperfect. The pupil, however, remains extremely small. There is paralysis also of the upper half of the right facial nerve, and the right upper lid remains in any position that it may be 